\title{
Genotoxic and antigenotoxic effects of organic extracts of mushroom Agaricus blazei Murrill on V79 cells
}

\author{
Zaira da Rosa Guterres ${ }^{1}$, Mário Sérgio Mantovani ${ }^{1}$, Augusto Ferreira da Eira ${ }^{2}$, \\ Lúcia Regina Ribeiro ${ }^{3}$ and Berenice Quinzani Jordão ${ }^{1}$ \\ ${ }^{1}$ Universidade Estadual de Londrina, Departamento de Biologia Geral, Londrina, PR, Brazil. \\ ${ }^{2}$ Universidade Estadual Paulista 'Júlio de Mesquita Filho', Faculdade de Ciências Agronômicas, \\ Departamento de Produção Vegetal, Módulo de Cogumelos, Botucatu, SP, Brazil. \\ ${ }^{3}$ Universidade Estadual Paulista 'Júlio de Mesquita Filho', Departamento de Patologia, Botucatu, SP, \\ Brazil.
}

\begin{abstract}
Agaricus blazei Murrill, popularly known as the sun mushroom, is a native mushroom in SP, Brazil, that has been widely used in the treatment of cancer and many other pathologies in different parts of the world. A water-soluble protein-polysaccharide complex $(1 \rightarrow 6) \beta-D$-glucan has been isolated from its fruiting body that showed immune-modulation activity. From organic extracts, linoleic acid has been isolated and determined to be the main substance with antimutagenic activity. Using both the micronucleus (MN) and comet (single cell microgel electrophoresis) assays, this study determined the genotoxic and antigenotoxic potential of $A$. blazei (AB) obtained from commercial sources or the following strains: a) strains $A B$ 97/29 (young and sporulated phases); b) a mixture taken from $A B$ 96/07, $A B$ 96/09 and $A B$ 97/11 strains; and c) commercial mushrooms from Londrina, PR and Piedade, SP, designated as AB PR and AB SP, respectively. The extracts from these mushrooms were isolated in chloroform:methanol (3:1) and used in vitro at three different concentrations. V79 cells (Chinese hamster lung cells) were exposed to the extracts under pre-, simultaneous and post-treatment conditions, combined with methyl methanesulfonate (MMS). Under the circumstances of this study, these organic extracts did not show any genotoxic or mutagenic effects, but did protect cells against the induction of micronuclei by MMS.
\end{abstract}

Key words: Agaricus blazei, micronuclei, comet assay, V79 cells, mushroom extracts.

Received: April 1, 2004; Accepted: February 15, 2005.

\section{Introduction}

The relation between diet and health has been widely recognized by many people throughout the centuries. However, the relationship between diet and cancer has been pointed out only in the last decades (De Marini, 1998). As a consequence, diet in general is considered to be the largest source of mutagenic and carcinogenic substances for human beings. Various studies, including those using short-term assays, have helped to identify a great number of antimutagenic properties found in some foods such as: $\beta$-carotene, ascorbic acid, linoleic acid, $\alpha$-tocopherol, vanillin, chlorophyllin, polyphenols and components found in black and green teas and mushrooms (Brockman et al., 1992; Lohman et al., 2001). For this rea-

Send correspondence to Berenice Quinzani Jordão. Universidade Estadual de Londrina, Departamento de Biologia Geral, Caixa Postal 6001, 86.051-990 Londrina, PR, Brazil. E-mail: berejordao@uel.br. son, the finding of these substances in natural foods is extremely important not only due to their nutritional value but also as a prophylactic agent against diseases such as cancer (Ferguson, 1994).

Although various mushrooms are used nowadays as a medicine or food in some western countries, their use is more common in the Far East (Chang, 1996). Immunological, hypocholesterolemic, antiviral, antibacterial and antiparasitic activities have been ascribed to some substances isolated from higher species of Basidiomycetes (Mizuno, 1995; Wasser and Weis, 1999; Ooi and Liu, 1999), among these, Agaricus blazei Murrill. Moreover, this mushroom has been used to combat physical and emotional stress, improve the quality of life for diabetics, and fight diseases such as osteoporosis and gastric ulcer, and as an effective antioxidant and anticarcinogen. Nevertheless, since some Basidiomycetes species are poisonous, it is necessary to obtain epidemiological and experimental data on the beneficial effects of the extracts of the species studied. 
A protein-polysaccharide complex $(1 \rightarrow 6) \beta$-D-glucan has been isolated from crude aqueous extracts of the fruiting body of the Basidiomycete $A$. blazei. This complex was characterized by a growth inhibitory effect on sarcoma-180 implanted in mice, showing immunomodulatory and immuno-stimulating properties (Itoh et al., 1994), possibly due to immunological mechanisms involving the action of various immuno-competent cells. A selective tumoricidal effect of soluble proteoglucan extracted from $A$. blazei Murrill, mediated via natural killer-cell activation and by the induction of apoptosis, was demonstrated by Fujimiya et al. (1999). The $A$. blazei mushroom teas prepared from mixed strains (AB 96/07, AB 96/09 and AB 97/11) studied in vitro and in vivo, by Menoli et al. (2001) and Delmanto et al. (2001) respectively, showed antimutagenic activity against methyl methanesulfonate (MMS) and cyclophosphamide. On the other hand, a previous study conducted by Guterres et al. (2004), which assessed the antimutagenicity effect of aqueous extracts from young and sporulated basidiocarps of the AB 97/29 strain in vitro, could not show a protective effect against MMS. Meanwhile, teas of the commercial mushroom from Piedade, SP (AB SP) showed antimutagenic activity in all of the protocols used and the ones from Londrina, PR (AB PR) showed antimutagenic activity only in a pre-treatment protocol.

The antimutagenic effect of $A$. blazei extracts was also studied by the Ames assay, against the mutagen benzo(a)pyrene, when linoleic acid (an unsaturated fatty acid that represents $70-78 \%$ of total lipids of its fruiting body) isolated from $A$. blazei with chloroform:methanol (2:1), was associated with this effect in Salmonella (Osaki et al., 1994). The antimutagenicity of fatty acids is believed to involve not only antimutagenic mechanisms (through micelle formation around the mutagen) but also bioantimutagenic mechanisms (improving repair processes in the cell) (Hayatsu et al., 1988; Sasaki et al., 1994). This compound was first shown to prevent mammary carcinogenesis in murine models. Later, investigations uncovered a number of additional health benefits, including alleviating atherosclerosis and inflammation while enhancing immune function (Bassaganya et al., 2002).

In this work, $A$. blazei obtained from different regions were tested for their genotoxic and/or antigenotoxic effects against damage induced by MMS in V79 cells, using the micronucleus test and comet assay. By using three different concentrations of an organic extract in three different experimental protocols, pre-, post- and simultaneous treatments, it was possible to provide evidence that $A$. blazei may be a practical and effective protective agent against chemical mutagens or biomutagens.

\section{Materials and Methods}

\section{Cell culture conditions}

Chinese hamster lung fibroblasts, V79 cells, were grown as a monolayer in $25-\mathrm{cm}^{3}$ plastic culture flasks, for $\mathrm{MN}$ test and in test tubes of $2.5 \mathrm{~mL}$ for the comet test. Cells were cultivated in Ham's F10 nutrient mixture (GibcoBRL) plus Dulbecco's modified Eagle minimal essential medium (D-MEM-GibcoBRL) (1:1), supplemented with $10 \%$ fetal bovine serum, and grown at $37{ }^{\circ} \mathrm{C}$ in a BOD-type incubator. Under these conditions, the average cell cycle time was $12 \mathrm{~h}$.

\section{Organic extracts of Agaricus blazei}

Five organic extracts obtained from different mushrooms were studied in this work: AB 97/29 in the young and sporulated phases; $\mathrm{AB}$ mix (mixture of strains $\mathrm{AB}$ 96/07, AB 96/09 and AB 97/11); AB PR and AB SP, commercial products from Londrina, PR and Piedade, SP, respectively. According to Osaki et al. (1994), $1.5 \mathrm{~g}$ of the mushroom powder (milled and dehydrated) were mixed with distilled water $(40 \mathrm{~mL})$ at $100{ }^{\circ} \mathrm{C}$, followed by $10 \mathrm{~min}$ of magnetic stirring. Afterwards, $40 \mathrm{~mL}$ chloroform:methanol (3:1) were added to the mixture, stirred for an additional $4 \mathrm{~h}$, and then filtered. After evaporation of the filtrate, a residue (3 mg) was obtained to which were added $400 \mu \mathrm{L}$ of dimethyl sulfoxide (DMSO) and $4.6 \times 10^{3} \mu \mathrm{L}$ of phosphate-buffered saline solution (PBS). These extracts were used at final concentrations of 20,40 and $80 \mu \mathrm{L} / \mathrm{mL}$ for the $\mathrm{MN}$ test and $60 \mu \mathrm{L} / \mathrm{mL}$ for the comet test.

\section{Micronucleus test}

Prior to use, V79 cells were seeded in $5 \mathrm{~mL}$ of fresh complete culture medium and grown for $25 \mathrm{~h}$. The following protocols were used in the test: a) $16 \mu \mathrm{L}$ DMSO + $284 \mu \mathrm{L}$ PBS (pH 7.4) - negative control; b) $50 \mu \mathrm{L}$ of methyl methanesulfonate (MMS, Aldrich, prepared immediately before the test) - positive control; c) treatment with each mushroom extract; d) treatment with organic extracts from strains AB 97/29 young and sporulated, AB mix, $\mathrm{AB} P R$ and $\mathrm{AB} \mathrm{SP}$, followed by MMS pre-treatment; e) simultaneous treatment with organic extracts and MMS; and f) treatments with organic extracts after treating with MMS - post-treatment. Organic extracts were tested at three different concentrations (20, 40 and $80 \mu \mathrm{L} / \mathrm{mL}$ ) and MMS at a final concentration of $4 \mathrm{x}$ $10^{-4} \mathrm{M}$, and each substance was applied for $1 \mathrm{~h}$. After each treatment, the cells were washed twice with $5 \mathrm{~mL}$ PBS ( $\mathrm{pH} 7.4$ ), and $5 \mathrm{~mL}$ of complete culture medium were added containing cytochalasin - B $(10 \mu \mathrm{L} / \mathrm{mL})$ for $18 \mathrm{~h}$, to stop cytokinesis and to obtain binucleated cells. All the protocols were carried out in triplicate. The procedures employed for harvesting and staining were according to Salvadori et al. (1993). The criteria employed for the anal- 
ysis of the micronuclei and binucleated cells were established by Fenech (2000). The slides were coded and scored blindly and one thousand binucleated cells were counted per slide.
The percent reduction in the number of cells treated with extracts that showed antimutagenic effect was calculated according to Manoharan and Banerjee (1985) and Waters et al. (1990) by the following formula:

$$
\text { reduction }(\%)=\frac{\text { number of cells with } \mathrm{MN} \text { in } \mathrm{A} \text { - number of cells with } \mathrm{MN} \text { in } \mathrm{B}}{\text { number of cells with } \mathrm{MN} \text { in } \mathrm{A} \text { - number of cells with } \mathrm{MN} \text { in } \mathrm{C}}
$$

where A is the group of cells treated with MMS (positive control), B the group of cells with the extract plus MMS, and $\mathrm{C}$ the negative control.

\section{Comet test}

V79 cells in early log-phase had been seeded in complete culture medium for $25 \mathrm{~h}$. At the end, they were exposed to different treatments. The following protocols were used: a) PBS (pH 7.4) - negative control; b) MMS - positive control; c) mushroom extracts; d) pre-treatment with mushroom extracts prior to MMS; e) simultaneous treatment with mushroom extracts and MMS; and f) post-treatment with mushroom extracts after MMS. Protocol c) was applied specifically to assess genotoxic effects and protocols d) to f) to assess antigenotoxicity. All of the different mushroom extracts were used at a final concentration of $60 \mu \mathrm{L} / \mathrm{mL}$ of complete medium. MMS was used at a final concentration of $1.2 \times 10^{-4} \mathrm{M}$ and all the treatments with mushroom extracts or MMS were applied for $1 \mathrm{~h}$, and repeated three times. At the end of the treatments, cells were trypsinized $(200 \mu \mathrm{L}$ at $0.025 \%)$. The cells were harvested by centrifugation and the pellet was gently resuspended. An aliquot of $10 \mu \mathrm{L}$ of cell suspension was mixed with $120 \mu \mathrm{L}$ of $0.5 \%$ low melting point agarose at $37{ }^{\circ} \mathrm{C}$, and rapidly spread onto coded microscope slides pre-coated with $1.5 \%$ normal melting point agarose. Coverslips were added to the slides and these were maintained at $4{ }^{\circ} \mathrm{C}$ for $10 \mathrm{~min}$. Then, the coverslips were removed gently and the slides were immersed in cold, freshly made lysis solution composed of $89 \mathrm{~mL}$ of a stock solution $(2.5 \mathrm{M} \mathrm{NaCl} ; 100 \mathrm{mM}$ EDTA; $10 \mathrm{mM}$ Tris; $\mathrm{pH}$ set to 10.0 with $8 \mathrm{~g} \mathrm{NaOH}, 890 \mathrm{~mL}$ of distilled water and $1 \%$ sodium lauroyl sarcosine), plus $1 \mathrm{~mL}$ of Triton X-100 and $10 \mathrm{~mL}$ of DMSO. Protected from the light, the slides were placed at $4{ }^{\circ} \mathrm{C}$ for at least $1 \mathrm{~h}$. Afterward, they were placed in a gel box, set in an ice bath (around $4{ }^{\circ} \mathrm{C}$ ) and an electrophoresis buffer $(300 \mathrm{mM}$ $\mathrm{NaOH}$ and $1 \mathrm{mM}$ EDTA - $\mathrm{pH}>13.0$, prepared from a stock solution of $10 \mathrm{~N} \mathrm{NaOH}$ and $200 \mathrm{mM}$ EDTA - pH 10.0) was then poured into the box in order to cover the slides for a period of $20 \mathrm{~min}$ in the dark to allow the DNA to unwind. The gels were electrophoresed for $20 \mathrm{~min}$, under $25 \mathrm{~V}$ and $300 \mathrm{~mA}(\sim 0.8 \mathrm{~V} / \mathrm{cm})$ conditions. Afterward, the slides were neutralized for $15 \mathrm{~min}$, dried at room temperature and fixed with $100 \%$ ethanol for $10 \mathrm{~min}$. They were evaluated blindly and immediately. Comet patterns were classified into four different categories $(0,1,2$, and 3$)$, according to damage level and the scores of the comets were calculated according to Speit and Hartmann (1999).

\section{Statistical analysis}

The data for the micronucleus and comet assays obtained in three replicate tests were analyzed statistically by ANOVA and by Student's t-test, comparing the treated groups with their controls. The level of statistical probability was considered at $\mathrm{p}<0.05$.

\section{Results}

\section{Micronucleus test}

The results obtained in $\mathrm{MN}$ test (data not shown) demonstrated the absence of a mutagenic effect of the $A$. blazei organic extract at any of the concentrations studied, which was confirmed statistically.

The results of experiments designed to assess the antimutagenicity of $A$. blazei extracts against MMS, using different protocols of pre-treatment, simultaneous treatment, and post-treatment, are shown in Table 1. The extracts obtained from strain AB 97/29 in both development phases (young and sporulated), AB mix, AB PR and AB SP showed antimutagenic activity at all three concentrations tested, demonstrating the ability to reduce the MN frequencies between 50 and $94 \%$ relative to the negative control. The highest percent reduction in MN frequencies (from 67 to $94 \%$ ) was obtained at a concentration of $80 \mu \mathrm{L} / \mathrm{mL}$ for all organic extracts with simultaneous treatment. The lowest reductions occurred in the following cases: a) $\mathrm{AB}$ mix (20 $\mu \mathrm{L} / \mathrm{mL}$ ) with simultaneous treatment $(50.7 \%)$; b) sporulated AB 97/29 (40 $\mu \mathrm{L} / \mathrm{mL})$ with pre-treatment $(62 \%)$; and c) sporulated AB 97/29 $(20 \mu \mathrm{L} / \mathrm{mL})$ with post-treatment $(59.25 \%)$. Therefore, all reduction rates of $\mathrm{MN}$ frequencies were greater than $50 \%$.

\section{Comet test}

The results obtained in relation to genotoxicity assessment of the organic extracts of $A$. blaze $i$ in comet assay (results not shown in this work) demonstrated that these extracts were not genotoxic, since the scores obtained after the treatments did not differ from the ones of the negative control.

The results from the pre-, simultaneous and post-treatments conducted to assess the antigenotoxicity of A. blazei against MMS are shown in Table 2. All the different extracts tested showed reduced damage (albeit less than 
Table 1 - Mean frequencies of MN in vitro on V79 cells for antimutagenicity assessment after pre-, simultaneous and post-treatments with organic extracts of A. blazei against MMS. Means of 3 repetitions.

\begin{tabular}{|c|c|c|c|c|c|c|c|}
\hline \multirow{2}{*}{\multicolumn{2}{|c|}{$\begin{array}{l}\text { Treatment* } \\
(\mu \mathrm{L} / \mathrm{mL})\end{array}$}} & \multicolumn{2}{|c|}{ Pre-treatment } & \multicolumn{2}{|c|}{ Simultaneous treatment } & \multicolumn{2}{|c|}{ Post-treatment } \\
\hline & & \multirow{2}{*}{$\frac{\text { Mean } \pm S D}{16.60 \pm 0.50}$} & \multirow[t]{2}{*}{$\% \mathrm{R}$} & \multirow{2}{*}{$\frac{\text { Mean } \pm \mathrm{SD}}{21.00 \pm 1.70}$} & \multirow[t]{2}{*}{$\% \mathrm{R}$} & \multirow{2}{*}{$\frac{\text { Mean } \pm \mathrm{SD}}{15.66 \pm 2.00}$} & \multirow[t]{2}{*}{$\% \mathrm{R}$} \\
\hline Control & & & & & & & \\
\hline MMS & & $41.33 \pm 1.10$ & & $43.33 \pm 2.50$ & & $42.66 \pm 2.50$ & \\
\hline \multirow[t]{3}{*}{$\mathrm{AB} Y$} & 20 & $19.33 \pm 2.08 * * *$ & 89.05 & $29.66 \pm 0.50 * * *$ & 61.22 & $25.99 \pm 0.00 * * *$ & 65.40 \\
\hline & 40 & $22.00 \pm 1.00 * * *$ & 78.35 & $28.00 \pm 1.00 * * *$ & 68.65 & $24.66 \pm 2.30 * * *$ & 66.66 \\
\hline & 80 & $23.33 \pm 3.50 * * *$ & 74.00 & $25.33 \pm 2.50 * * *$ & 80.60 & $24.66 \pm 5.03 * * *$ & 66.66 \\
\hline \multirow[t]{3}{*}{ AB S } & 20 & $23.00 \pm 3.60 * * *$ & 74.30 & $26.33 \pm 2.08 * * *$ & 76.13 & $26.66 \pm 2.08 * * *$ & 59.25 \\
\hline & 40 & $26.00 \pm 6.50 * * *$ & 62.14 & $25.66 \pm 3.05 * * *$ & 79.13 & $22.66 \pm 2.08 * * *$ & 74.07 \\
\hline & 80 & $21.00 \pm 4.00 * * *$ & 82.40 & $22.33 \pm 1.15 * * *$ & 94.04 & $22.66 \pm 2.08 * * *$ & 74.07 \\
\hline \multirow[t]{3}{*}{ AB Mix } & 20 & $22.00 \pm 3.40^{* * *}$ & 78.35 & $32.00 \pm 2.60 * * *$ & 50.73 & $25.33 \pm 1.50 * * *$ & 64.18 \\
\hline & 40 & $21.66 \pm 3.05 * * *$ & 79.73 & $30.33 \pm 3.00 * * *$ & 59.70 & $22.00 \pm 4.00 * * *$ & 76.52 \\
\hline & 80 & $21.33 \pm 0.50 * * *$ & 81.03 & $28.33 \pm 0.50 * * *$ & 67.17 & $22.33 \pm 1.15 * * *$ & 75.30 \\
\hline \multirow[t]{3}{*}{$\mathrm{AB} P \mathrm{PR}$} & 20 & $22.33 \pm 2.50 * * *$ & 77.02 & $28.66 \pm 3.50 * * *$ & 65.70 & $21.33 \pm 1.50 * * *$ & 79.00 \\
\hline & 40 & $23.33 \pm 0.50 * * *$ & 73.00 & $27.66 \pm 1.50 * * *$ & 70.17 & $25.00 \pm 2.00 * * *$ & 65.40 \\
\hline & 80 & $21.33 \pm 1.15^{* * *}$ & 81.07 & $25.00 \pm 2.60 * * *$ & 82.10 & $23.66 \pm 1.50 * * *$ & 70.40 \\
\hline \multirow[t]{3}{*}{ AB SP } & 20 & $22.00 \pm 2.60 * * *$ & 78.35 & $25.33 \pm 0.50 * * *$ & 80.60 & $22.00 \pm 2.00 * * *$ & 76.52 \\
\hline & 40 & $21.66 \pm 4.50 * * *$ & 79.73 & $25.66 \pm 0.50 * * *$ & 79.13 & $21.33 \pm 0.50 * * *$ & 79.00 \\
\hline & 80 & $21.00 \pm 1.00 * * *$ & 82.40 & $22.33 \pm 3.20 * * *$ & 94.04 & $22.00 \pm 1.00 * * *$ & 76.52 \\
\hline
\end{tabular}

*A. blazei (strain 97/29) in the development phases young (Y) and sporulated (S), A.blazei (AB Mix) - strains AB 96/07, AB 96/09 and AB 97/11, A. blazei (AB PR) - Londrina, PR, Brazil, A. blazei (AB SP) - Piedade, SP, Brazil, reduction percentage - \% R, *** p $<0.001$.

50\%), although the score reductions with $\mathrm{AB} 97 / 29$ (young phase) and $\mathrm{AB}$ mix, both in pre-treatment protocol, were not statistically significant.

\section{Discussion}

The results of the present investigation regarding the genotoxicity of the organic extracts of $A$. blazei mushroom based on the micronucleus and comet assays, in vitro, demonstrate clearly that the extracts obtained with chloroform:methanol $(3: 1)$ did not have genotoxic or mutagenic activity at all, regardless of their origin or concentration.

On the other hand, analyzing the antigenotoxicity of these organic extracts against MMS in different protocols using the MN test, the same showed effective protection, regardless of the dose. These results suggest that all organic extracts of Agaricus blazei were effective antimutagens, protecting the cells against clastogens and/or aneugens that cause micronuclei formation.

Furthermore, with the comet assay, a reduction in DNA damage was observed and statistically confirmed in the greater number of protocols analyzed. AB SP extract showed the highest efficiency, while those of AB 97/29 (young phase) and $\mathrm{AB}$ mix did not exhibit any antigenotoxic activity in pre-treatment. These variable responses observed in the comet assay correspond with those reported by Menoli et al. (2001).
The different cellular responses obtained with $\mathrm{MN}$ and comet assays could be related to the different end-points evaluated in each test, since the lesions detected by the comet assay are DNA strand breaks and alkali labile lesions, which are not necessarily the same that form micronuclei (chromosomal fragmentation or dispersion of whole chromosomes). On the other hand, the divergent results between both tests could also reflect the differences in the $\mathrm{MN}$ and comet protocols, since the time used in the former test would allow the occurrence of DNA repair which would not be possible in the latter. In the comet protocol, the cells are harvested immediately after treatment, without any opportunity for the repair of damages.

According to Kuroda et al. (1992) and Kojima et al. (1992), the differences found in the three different protocols used in the present study could lead to a better manner of examining the antimutagenicity mechanisms of tested substances. They may act directly on the mutagenic molecule by inactivating it (desmutagens) or, indirectly, by blocking the mutagenic process by increasing the fidelity in DNA replication or by stimulating DNA damage error-free repair (bio-antimutagenesis) (De Flora, 1998). Related to this, desmutagenesis could be detected with pre-treatment and simultaneous treatment, while bio-antimutagenicity could be better detected with post-treatment. Moreover, the results obtained with the three forms of treatment did not 
Table 2 - Mean frequencies of cells in each category and damage indices - (mean scores) in the comet assay for antimutagenicity assessment in V79 cells after pre-, simultaneous and post-treatments with organic extracts of $A$. blazei against MMS. 100 nuclei were analyzed and the means are from 3 repetitions.

\begin{tabular}{|c|c|c|c|c|c|c|}
\hline \multirow{2}{*}{$\begin{array}{l}\text { Treatment* } \\
(60 \mu \mathrm{L} / \mathrm{mL})\end{array}$} & \multirow{2}{*}{$\begin{array}{l}\text { Number of cells } \\
\text { with comet }\end{array}$} & \multicolumn{4}{|c|}{ Comet Class } & \multirow[t]{2}{*}{ Score } \\
\hline & & 0 & 1 & 2 & 3 & \\
\hline \multicolumn{7}{|l|}{ Pre-treatment } \\
\hline Control & 76 & 74.66 & 22.66 & 2.33 & 0.33 & 28.33 \\
\hline MMS & 298 & 0.66 & 30.33 & 48.00 & 21.00 & 189.33 \\
\hline $\mathrm{AB} Y$ & 297 & 1.00 & 35.66 & 41.66 & 21.33 & 183.00 \\
\hline $\mathrm{AB} \mathrm{S}$ & 300 & 0.00 & 50.33 & 34.33 & 15.33 & $165.00 *$ \\
\hline AB Mix & 300 & 0.00 & 44.00 & 40.33 & 15.66 & 171.66 \\
\hline AB PR & 300 & 0.00 & 43.66 & 43.66 & 12.66 & $169.00 *$ \\
\hline AB SP & 300 & 0.00 & 63.33 & 32.66 & 4.00 & $140.66^{*}$ \\
\hline \multicolumn{7}{|c|}{ Simultaneous treatment } \\
\hline Control & 67 & 77.66 & 20.33 & 1.33 & 0.66 & 25.00 \\
\hline MMS & 300 & 0.00 & 31.33 & 39.33 & 29.33 & 198.00 \\
\hline $\mathrm{AB} Y$ & 251 & 16.33 & 51.66 & 20.66 & 11.33 & $127.00 *$ \\
\hline $\mathrm{AB} \mathrm{S}$ & 247 & 17.66 & 53.00 & 21.66 & 7.66 & $119.33 *$ \\
\hline AB Mix & 264 & 12.00 & 55.66 & 23.66 & 8.66 & $129.00 *$ \\
\hline AB PR & 265 & 11.66 & 50.66 & 30.00 & 7.66 & $133.66^{*}$ \\
\hline AB SP & 261 & 13.00 & 69.66 & 14.33 & 3.00 & $112.66^{*}$ \\
\hline \multicolumn{7}{|c|}{ Post-treatment } \\
\hline Control & 80 & 73.33 & 25.00 & 1.33 & 0.33 & 28.66 \\
\hline MMS & 300 & 0.00 & 28.33 & 50.00 & 21.66 & 193.33 \\
\hline AB Y & 298 & 0.66 & 62.33 & 31.00 & 6.00 & $142.33 *$ \\
\hline AB S & 300 & 0.00 & 61.33 & 31.33 & 7.33 & $146.00 *$ \\
\hline AB Mix & 296 & 1.33 & 56.00 & 37.33 & 5.33 & $146.66^{*}$ \\
\hline AB PR & 300 & 0.00 & 57.33 & 36.33 & 6.33 & $149.00 *$ \\
\hline AB SP & 300 & 0.00 & 77.00 & 21.33 & 1.66 & $124.66^{*}$ \\
\hline
\end{tabular}

*A. blazei (strain 97/29) in the development phases young (Y) and sporulated (S), A.blazei (AB Mix) - lineages AB 96/07, AB 96/09 and AB 97/11, A. blazei (AB PR) - Londrina, PR, Brazil, A. blazei (AB SP) - Piedade, SP, Brazil, *p $<0.05$.

differ enough to suggest the exact mechanism action in the protection against MMS. Apparently, in this case, both mechanisms are present, as previously suggested by Hayatsu et al. (1988) and Sasaki et al. (1994).

In the present investigation, the chemical components from the organic extracts were not identified. However, they are likely similar to those detected by Osaki et al. (1994) since the same extraction method was used. The latter investigators demonstrated that linoleic acid was responsible for the antimutagenic activity observed. Linoleic acid (cis-9, 12-octadecadienoic acid) belongs to the group of cis unsaturated fatty acids. Conjugated linoleic acid (CLA) is a generic name for isomers of octadecadienoic acid and has been reported to exert various beneficial physiologic effects, such as reducing body fat level in mice, rats and obese humans (Yamasaki et al., 2003). Also it is an effective anticarcinogenic, antidiabetic and antilipogenic agent in the diet of laboratory animals (Paniza et al., 2001). However, little is known regarding the mechanisms of ac- tion of these CLA. In particular, cell signaling mechanisms are regulated by CLA which can explain their anticancer properties (Wahle and Hey, 2002).

Luiz et al. (2003) evaluated organic extracts of $A$. blazei strain AB 97/11 obtained under conditions identical to those in the present study. Using chromosome aberration and sister chromatid exchange assays, they found that these extracts exhibit bio-antimutagenic type protective activity, since the results indicated effective action of extracts on DNA repair mechanisms. This effect was associated with the probable participation of linoleic acid.

The present work suggests the presence of this same substance in the $A$. blazei organic extracts used and its participation in the biological effects observed, acting alone or together with other components.

In addition, it seems that one or more substances with antimutagenic properties were present in the organic extracts of the various kinds of $A$. blazei mushroom analyzed, regardless of the origin, the way of planting, the covering 
protection used on the crops or even the harvest time. This variation does not seem to interfere in their biological responses, unlike what occurs with aqueous extracts of $A$. blazei mushroom acquired from the some different sources, in which not all of them show antimutagenic activity (Guterres et al., 2004).

Further studies are therefore required to better characterize the properties of Agaricus blazei mushroom, dealing with the identification of the active chemical components and the application of different test systems, other experimental protocols and other end-points, to contribute to new discoveries with therapeutic results.

\section{Acknowledgements}

Financial support provided by FAPESP, SP, Brazil. We would also like to thank Dr. A. Leyva for reading the manuscript.

\section{References}

Bassaganya-Riera J, Hontecillas R and Beitz DC (2002) Colonic anti-inflammatory mechanisms of conjugated linoleic acid. Clin Nutr 21:451-459.

Brochman E, Stack HF and Waters MD (1992) Antimutagenicity profiles of some natural substances. Mutat Res 267:157-172.

Chang R (1996) Functional properties of edible mushrooms. Nutrition Rev 54:11-15.

De Flora S (1998) Mechanisms of inhibitors of mutagenesis and carcinogenesis. Mutat Res 402:151-158.

De Marini M (1998) Dietary interventions of human carcinogenesis. Mutat Res 400:457-465.

Delmanto RD, Lima PLA, Sugui MM, da Eira AF, Salvadori DMF, Speit G and Ribeiro LR (2001) Antimutagenic effect of Agaricus blazei Murrill mushroom on the genotoxicity induced by cyclophosphamide. Mutat Res 496:15-21.

Fenech M (2000) The in vitro micronucleus technique. Mutat Res 455:81-95.

Ferguson LR (1994) Antimutagens as cancer chemopreventive agents in the diet. Mutat Res 307:395-410.

Fujimiya Y, Susuki Y, Katakura R and Ebina T (1999) Tumor-specific cytoxicity and immunopotentiating effects of relatively low molecular weight products derived from the basidiomycete Agaricus blazei Murrill. Anticancer Res 19:113-118.

Guterres ZR, Mantovani MS, Eira AF, Ribeiro LR and Jordão BQ (2004) Variation of the antimutagenicity effects of water extracts of Agaricus blazei Murrill in vitro. Toxicol in Vitro 18:301-309. Available online 13 November 2003 (doi: 10.1016/j.tiv.2003.09.003).

Hayatsu H, Arimoto S and Negishi T (1988) Dietary inhibitors of mutagenesis and carcinogenesis. Mutat Res 202:429-446.

Itoh H, Amano H and Noda H (1994) Inhibitory action of a (1-6) $\beta$-glucan-protein complex (F III-2-b) isolated from Agaricus blazei Murrill ("himematsutake") on meth a fibrosarcoma bearing mice and its antitumor mechanism. Jap $\mathrm{J}$ of Pharmacol 6:265-271.

Kojima H, Konishi H and Kuroda Y (1992) Combined mutagenicity of methyl methanesulfonate and ethyl methanesulfonate in Chinese hamster V79 cells. Mutat Res 266:171-180.
Kuroda Y, Jain AK, Tezuka H and Kada T (1992) Antimutagenicity in cultured mammalian cells. Mutat Res 267:201-209.

Lohman PHM, Gentile JM, Gentile G and Ferguson LR (2001) Antimutagenesis/anticarcinogenesis screening, methods and biomarkers. Mutat Res 496:1-4.

Luiz RC, Jordão BQ, Eira AF, Ribeiro LR and Mantovani MS (2003) Mechanisms of anticlastogenicity of Agaricus blazei Murill mushroom organic extracts in wild type $\mathrm{CHO}\left(\mathrm{K}_{1}\right)$ and repair deficient (xrs 5) cells by chromosome aberration and sister chromatid exchange assays. Mutat Res 528:75-79.

Manoharan K and Banerjee MR (1985) $\beta$-carotene reduces sister chromatid exchange induced by chemical carcinogens in mouse mammary cells in organ culture. Cell Biol Int Rep 9:783-789.

Menoli RCRN, Montovani MS, Ribeiro LR, Speit G and Jordão BQ (2001) Antimutagenic effects of the mushroom Agaricus blazei Murrill extracts on V79 cells. Mutat Res 496:5-13.

Mizuno T (1995) Bioactive biomolecules of mushrooms - Food, function and medicinal effect of mushroom fungi. Food Rev Int 11:7-21.

Ooi VEC and Liu F (1999) A review of pharmacological activities of mushroom polysaccharides. Int $\mathrm{J}$ of Med Mushrooms 1:195-206.

Osaki Y, Kato T, Yamamoto K and Okubo J (1994) Antimutagenic and bactericidal substances in the fruit body of a basidiomycete Agaricus blazei. Yakugaku - Zasshi 114:342-350.

Paniza M, Park Y and Cook M (2001) The biologically active isomers of conjugated linoleic acid. Prog Lipid Res 40:283298.

Salvadori DMF, Ribeiro LR and Natarajan AT (1993)The anticlastogenicity of $\beta$-carotene evaluated in human hepatoma cells. Mutat Res 303:151-156.

Sasaki Y, Sakaguchi M, Yamagish T, Yamada H and Shirasu Y (1994) Bio-anticlastogenic effects of unsaturated fatty acids included in fish oil- docosahexaenoic acid, docosapentaenoic acid, and eicosapentaenoic acid- in cultured Chinese hamster cells. Mutat Res 320:9-22.

Speit G and Hartmann A (1999) The comet assay (Single Cell Gel Test) - A sensitive genotoxicity test for the detection of DNA damage and repair. In: Henderson DS (ed) Methods in Molecular Biology. Humana Press, Berlin, pp 203-212.

Wahle KWJ and Hey SD (2002) Cell signal mechanisms, conjugated linoleic acids (CLAs) and anti-tumorigenesis. Prostaglandins, Leukotrienes and Fatty Acids 67:183-186.

Wasser SP and Weis AL (1999) Therapeutic effects of substances occurring in higher Basidiomycetes mushrooms: Modern perspective. Critical Rev in Inmunol 19:65-96.

Waters MD, Brady AL, Stack HF and Brockman HE (1990) Antimutagenicity profiles for some model compounds. Mutat Res 238:57-85.

Yamasaki M, Ykeda A, Oji M, Tanaka Y, Hirao A, Kasai M, Iwata Y, Tachibana H and Yamada K (2003) Modulation of body fat and serum leptin levels by dietary conjugate linoleic acid in Sprague Dawley rats fed various fat-level diets. Nutrition 1:30-35.

Associate Editor: Carlos F.M. Menck 